\title{
Nutritional Attributes as Predictors of Coronary Heart Disease
}

\author{
Jehad H. Elhissi1, Danuta N. Sukkar², Mazen A. El-Sakka ${ }^{3}$ \\ ${ }^{1}$ Faculty of Medicine, Al-Azhar University, Gaza, Palestine \\ ${ }^{2}$ Al-Remal Primary Health Care Center, Ministry of Health, Gaza, Palestine \\ ${ }^{3}$ Faculty of Pharmacy, Al-Azhar University, Gaza, Palestine \\ Email: ${ }^{\text {drdanuta@hotmail.com }}$
}

Received 17 October 2014; revised 25 November 2014; accepted 19 December 2014

Copyright (C) 2014 by authors and Scientific Research Publishing Inc.

This work is licensed under the Creative Commons Attribution International License (CC BY). http://creativecommons.org/licenses/by/4.0/

cC) (i) Open Access

\section{Abstract}

Background: Diet is an important modifiable risk factor for coronary heart disease (CHD). However, the influence of some groups of food intake on CHD has shown inconsistent findings. Objectives: This study aimed to identify the relation of the dietary habits, Vitamin D, serum lipids, and anthropometric measures of the participants with CHD. Methods: A retrospective case-control study was conducted at Al-Remal Clinic, Gaza City. The study included 50 cases of symptomatic CHD and 50 controls, chosen by convenience sampling method. Data were collected by direct methods that included measurement of serum levels of lipids and Vitamin D, and indirect methods using a structured interview questionnaire. Results: The mean of servings per day of fruits and vegetables was lower in CHD patients than controls $(P=0.004$, and $P=0.001$, respectively). Vitamin $D$ deficiency prevailed in CHD patients (odds ratio, 3.78; 95\% confidence interval, 1.65 - 8.65). The mean serum level of triglycerides was higher among cases $(P=0.02)$, while the mean of high-density lipoprotein cholesterol was lower in CHD patients $(P=0.001)$. Waist circumference $(\mathrm{mean})$ was higher among cases $(P=\mathbf{0 . 0 1})$. Conclusion: Traditional risk factors including unhealthy diet, and Vitamin D deficiency could be associated with the development of CHD.

\section{Keywords}

Coronary Heart Disease, Unhealthy Diet, Vitamin D, Hyperlipidemia, Gaza City

\section{Introduction}

Cardiovascular diseases (CVD) are the leading cause of death worldwide. In 2008, 17.3 million people died

${ }^{*}$ Corresponding author. 
from CVD, representing 30\% of all global deaths. Of these deaths, 7.3 million were due to coronary heart disease [1]. Cardiovascular diseases were the first leading cause of death (22.4\%) in West Bank (Palestine) in 2011 [2].

Coronary heart disease (CHD) is caused by atherosclerosis (ATS) of the coronaries [3]. Atherosclerosis is a chronic inflammation of the arteries in response to the biological effects of the risk factors. It starts with the action of oxidative, hemodynamic, or biochemical stimuli, and of inflammatory factors on the endothelial cells, which change their permeability and retain blood-borne monocytes and low-density lipoprotein cholesterol (LDL-C). Further, endothelial and smooth-muscle cells proliferate, produce extracellular matrix, and form the fibrous cap over the atheromatous plaque. Plaques producing flow-limiting stenoses manifest clinically as stable angina, while those producing thrombi that interrupt the blood flow manifest as unstable angina or myocardial infarction [4].

The conventional risk factors for CHD include age (over 45 years in men and over 55 years in women), family history of premature heart disease, and race: African Americans and Asians are at higher risk. Among modifiable risk factors for CHD are mentioned: high blood cholesterol (specifically, LDL-C), high blood pressure, cigarette smoking, diabetes mellitus, obesity, physical inactivity, metabolic syndrome, mental stress, and depression [5]. Diet is an important risk factor for CVD that can be modified [6]. An adequate intake of fruits and vegetables reduces the risk of CVD. Diets low in fruits and vegetables are estimated to cause 1.7 million (2.8\%) of deaths worldwide. A high intake of saturated and trans-fatty acids increases the risk of heart disease, while their replacement with polyunsaturated vegetable oils lowers CHD risk [7]. The scientific literature has shown that some diets have impacts on health [6].

The evidence from prospective studies has shown that high serum levels of LDL-C are a major risk factor for CHD [8]. Population studies have consistently demonstrated that high-density lipoprotein cholesterol (HDL-C) levels and the risk of CHD are inversely associated [9]. In atherogenic dyslipidemia abnormal triglycerides (TG) values are associated with high levels of LDL-C and low levels of HDL-C [10].

The two major forms of Vitamin D are Vitamin D3 (cholecalciferol) and Vitamin D2 (ergocalciferol). Vitamin D2 is found in plants [11]. Vitamin D3 is synthetized in skin from 7-dehydrocholesterol under solar ultraviolet B radiation. Most people depend on sun for their requirement of Vitamin D [12]. Foods containing Vitamin D are few, including fatty fish (salmon, mackerel, tuna, sardines, and cod liver oil) [11], and egg yolk [13]. Other sources are fortified foods (e.g. dairy products, cereals, flour, and orange juice), and dietary supplements [11]. To become active Vitamin D undergoes hydroxylation in liver to form 25(OH)D, then in kidney to form 1, 25(OH)2D, which is the active form. Besides intestine and bone, Vitamin D has receptors and acts in other systems such as immune, cardiovascular (CV), muscle, pancreas, and brain. One of the major biological functions of Vitamin D is to maintain calcium homeostasis [14]. Vitamin D increases the efficiency of calcium and phosphorus absorption in intestine [13]. Vitamin D participates indirectly in bone mineralization [14]. Vitamin D deficiency in adults can precipitate osteoporosis, and cause osteomalacia and muscle weakness. Vitamin D can help lower the risk of chronic diseases such as common cancers, autoimmune diseases, and CVD [13]. The role of Vitamin D in CV system is gaining interest. Low Vitamin D levels have been associated to higher coronary artery calcium scores and impaired endothelial function [15]. Vitamin D deficiency has been linked to hypertension, diabetes mellitus, inflammation, increased risk of atherosclerosis and CVD events. The potential mechanisms of Vitamin D deficiency in CV system include the up-regulation of the renin-angiotensin-aldosterone system, increasing levels of parathyroid hormone, and increasing insulin resistance [11].

The Food and Nutrition Board (FNB) at the Institute of Medicine (US) established that Recommended Dietary Allowance (RDA) for Vitamin D is $400 \mathrm{IU}$ in the first year of life, $600 \mathrm{IU}$ between 1 and 70 years, and 800 IU after 70 years [16].

Non-communicable diseases (NCDs) were responsible for more than 50\% of deaths in Gaza in 2013 [17]. As mentioned, CVD are the first leading cause of death in Palestine. The chances of having CHD of an individual can be decreased by managing modifiable risk factors such as unhealthy diet and hyperlipidemia. The aims of this study are to reveal the relation of dietary habits, Vitamin D, serum lipids, and anthropometric measures with CHD.

\section{Methods}

The data were extracted from a case-control study that was conducted in Partial Fulfillment of the Requirements for the Degree of Master in Clinical Nutrition at the Faculty of Pharmacy, Al-Azhar University-Gaza-Palestine 
(2013). The study was carried out at Al-Remal Primary Health Care Center in Gaza city from February to December, 2013. The study included adults $\geq 30$ years, both genders, as: 50 cases of coronary heart disease (CHD) registered at the clinic and 50 healthy controls, matched for age and gender with the cases. A convenience sampling method was used. The CHD cases included stable and unstable angina, and myocardial infarction, identified from clinical records file. For controls, CHD was excluded based on clinical evaluation and medical history. The exclusion criteria of the study were diabetes mellitus, renal, liver and bone disease, the use of lipid lowering medication and Vitamin D supplement. Written informed consent was obtained from participants. Ethical approval was obtained from the Faculty of Pharmacy and the Dean for Graduate Studies and Scientific Research of Al-Azhar University in Gaza, and from Palestinian Ministry of Health, Primary Health Care Directorate (Gaza).

Data were collected by direct methods that included anthropometric measurements [weight, height, waist circumference (WC), and calculated Body Mass Index (BMI)] and biochemical tests: serum lipid profile [total cholesterol (TC), LDL-C, HDL-C, and TG], and serum Vitamin D level. The indirect method used a structured face to face questionnaire that included the study variables and a semi-quantitative food-frequency questionnaire.

Weight, height, and waist circumference were measured by the standard protocol. BMI was calculated as: weight (kg)/[height $\left.(\mathrm{m})^{2}\right][18]$.

The participants fasted 12 hours. Lipid profile and Vitamin D levels were measured in serum. Total cholesterol was measured by CHOD-POD Liquid method (CHEMELEX, BARCELONA), HDL-C by CHOD-PAPmethod by photometric systems (Diasys Diagnostic Systems, Germany), and TG by colorimetric enzymatic test using glycerol-3 phosphate-oxidase (GPO) (Dyasis Diagnostic Systems, Germany). LDL-C was calculated by Friedewald Formula: [LDL-C] $=$ [total cholesterol] - [HDL-C] - [triglycerides/5] (mg/dl). High levels of TC, LDL-C and TG were considered as: $\geq 240 \mathrm{mg} / \mathrm{dl}, \geq 160 \mathrm{mg} / \mathrm{dl}$, and $\geq 200 \mathrm{mg} / \mathrm{dl}$, respectively; HDL-C < $40 \mathrm{mg} / \mathrm{dl}$ in men and $<50 \mathrm{mg} / \mathrm{dl}$ in women was considered low [19].

The serum Vitamin D levels were measured by ELISA method (Calbiotech Inc., Spring Valley, CA). Values of Vitamin D $\leq 25 \mathrm{ng} / \mathrm{ml}$ were considered deficiency, 26 - $80 \mathrm{ng} / \mathrm{ml}$ as optimal, and >80 ng/ml as possible toxicity [20].

The gathered data were analyzed by the Statistical Package for Social Sciences (SPSS) version 21. The data were expressed as percent and mean \pm standard deviation (SD). The odds ratio (OR) [95\% confidence interval (CI)] was presented as appropriate. Statistical tests used were Chi-square and independent t-test. A $P$-value $<$ 0.05 was considered statistically significant.

\section{Results}

\subsection{Socioeconomic Characteristics of the Study Participants}

The mean age of the CHD cases was $58.66 \pm 7.20$ years and that of controls was $57.68 \pm 7.20$ years.

Table 1 shows that a higher percentage of cases had a low socioeconomic status (education, working status, and financial income), with statistical significance. The percentage of smokers with CHD was higher (46\%) than controls (14\%), and the result reached statistical significance.

\subsection{Exposure to Stress}

As shown in Table 2, the percentage of patients with CHD exposed to Stressful Life Events exceeded that of healthy participants (64\% vs. 38\%, respectively), and the result was highly statistically significant. The investigator considered as "Stressful Life Events" the following: death of a close relative, presence at home of a close relative with severe chronic disease who needs special care, or house was demolished.

\subsection{Serum Lipids and Vitamin D Levels}

There was a statistically significant difference between the mean of serum Vitamin D levels in CHD patients and that of the healthy participants $(22.52 \pm 9.07 \mathrm{ng} / \mathrm{ml}$ versus $28.82 \pm 8.18 \mathrm{ng} / \mathrm{ml})$ (Table 3). The mean of TC, LDL-C, and TG was higher in cases group. For HDL-C, the mean was lower in cases, a statistically significant difference, as shown in Table 3.

As Table 4 shows, Vitamin D deficiency was higher in patients with CHD. The odds ratio for coronary heart disease in individuals with Vitamin D deficiency was 3.78 (95\% CI, 1.65 - 8.65). 
Table 1. Socioeconomic characteristics of the study participants.

\begin{tabular}{|c|c|c|c|c|}
\hline Variables & Cases No. (\%) & Controls No. (\%) & Total No. (\%) & $P$-value ${ }^{*}$ \\
\hline \multicolumn{5}{|c|}{ Educational level } \\
\hline Can read \& write & $26(52)$ & $10(20)$ & $36(36)$ & \multirow{4}{*}{0.001} \\
\hline Secondary & $16(32)$ & $9(18)$ & $25(25)$ & \\
\hline University \& higher & $8(16)$ & $31(62)$ & $39(39)$ & \\
\hline Total & $50(100)$ & $50(100)$ & $100(100)$ & \\
\hline \multicolumn{5}{|c|}{ Occupation } \\
\hline Working & $13(26)$ & $34(68)$ & $47(47)$ & \\
\hline Not working & $37(74)$ & $16(32)$ & $53(53)$ & 0.001 \\
\hline Total & $50(100)$ & $50(100)$ & $100(100)$ & \\
\hline \multicolumn{5}{|c|}{ Type of residency } \\
\hline Apartment & $22(44)$ & $27(54)$ & $49(49)$ & \\
\hline House & $28(56)$ & $23(46)$ & $51(51)$ & 0.31 \\
\hline Total & $50(100)$ & $50(100)$ & $100(100)$ & \\
\hline \multicolumn{5}{|c|}{ Satisfaction with financial income } \\
\hline Satisfied & $16(32)$ & $36(72)$ & $52(52)$ & \\
\hline Unsatisfied & $34(68)$ & $14(28)$ & $48(48)$ & 0.001 \\
\hline Total & 50 (100) & 50 (100) & $100(100)$ & \\
\hline \multicolumn{5}{|c|}{ Smoking } \\
\hline Smoker & $23(46)$ & 7 (14) & $30(30)$ & \\
\hline Non-smoker & $27(54)$ & $43(86)$ & $70(70)$ & 0.001 \\
\hline Total & $50(100)$ & $50(100)$ & $100(100)$ & \\
\hline
\end{tabular}

*Chi-square test was used; statistically significant at $P$-value $<0.05$.

Table 2. Stress exposure attributes of the study participants.

\begin{tabular}{ccccc}
\hline Variable & Cases No. (\%) & Controls No. (\%) & Total No. (\%) & P-value $^{*}$ \\
Exposed & $32(64)$ & Stressful life events & \\
Not exposed & $18(36)$ & $19(38)$ & $51(51)$ & 0.001 \\
Total & $50(100)$ & $31(62)$ & $49(49)$ & $100(100)$ \\
\hline
\end{tabular}

*Chi-square test was used; statistically significant at $P$-value $<0.05$.

Table 3. Comparing the serum Vitamin D and lipids levels of the study groups.

\begin{tabular}{ccccc}
\hline Lab findings & Cases $($ mean \pm SD) & Controls (mean \pm SD) & t & P-value $^{*}$ \\
\hline Serum Vitamin D $(\mathrm{ng} / \mathrm{ml})$ & $22.52(9.07)$ & $28.82(8.18)$ & -3.64 & 0.001 \\
TC $^{* *}(\mathrm{mg} / \mathrm{dl})$ & $211.7(52.6)$ & $201.54(28.97)$ & 1.19 & 0.23 \\
LDL-C (mg/dl) & $125.22(50.71)$ & $115.54(29.35)$ & 1.16 & 0.24 \\
HDL-C (mg/dl) & $47.02(14.88)$ & $59.90(16.22)$ & -4.1 & 0.001 \\
Triglycerides (mg/dl) & $195.2(118.92)$ & $136.24(51.94)$ & 3.21 & 0.02 \\
\hline
\end{tabular}

*Statistically significant at $P$-value $<0.05$. ${ }^{* *}$ Total cholesterol.

Table 4. Serum levels of Vitamin D of the study groups.

\begin{tabular}{cccc}
\hline Serum Vitamin D & Cases No. (\%) & Controls No. (\%) & Total No. (\%) \\
\hline Deficient level $<26 \mathrm{ng} / \mathrm{ml}$ & $32(64)$ & $16(32)$ & $48(48)$ \\
Optimum level $\geq 26-80 \mathrm{ng} / \mathrm{ml}$ & $18(36)$ & $34(68)$ & $52(52)$ \\
Total & $50(100)$ & $50(100)$ & $100(100)$ \\
\hline
\end{tabular}

Odds ratio, 3.78 (95\% confidence interval, 1.65 - 8.65). 
The results showed that $80 \%$ of cases had sufficient exposure to sun, and $84 \%$ of controls had the same $(P=$ $0.60)$.

\subsection{Anthropometric Measures [Body Mass Index (BMI) and Waist Circumference (WC)]}

The mean of BMI and WC was higher in CHD patients, as Table 5 shows.

\subsection{Dietary Habits}

As shown in Table 6, the patients with CHD consumed significantly less (mean of serving's number per day) dairy products, vegetables, fruits, and avocado. The mean of sweets intake was higher among cases than controls, a statistically significant difference.

The mean of daily intake of Vitamin D (IU/day) from food was $126.79 \pm 160.35$ IU in cases and $177.23 \pm$ $129.00 \mathrm{IU}$ in controls $(P=0.08)$.

Table 5. The mean of body mass index and waist circumference of the participants.

\begin{tabular}{ccccc}
\hline Variables & Cases $($ mean \pm SD) & Controls $($ mean \pm SD) & t & P-value $^{*}$ \\
\hline BMI $\left(\mathrm{kg} / \mathrm{m}^{2}\right)$ & $30.8(5.36)$ & $29.25(4.9)$ & 1.51 & 0.12 \\
WC $(\mathrm{cm})$ & $108.5(13.72)$ & $102.02(10.97)$ & 2.6 & 0.01 \\
\hline
\end{tabular}

${ }^{*}$ Statistically significant at $P$-value $<0.05$.

Table 6. Comparing the mean of servings of food per day between the participants.

\begin{tabular}{|c|c|c|c|c|c|}
\hline Variables & Study group & Mean & $\pm \mathrm{SD}^{* *}$ & $\mathbf{t}$ & $P$-value ${ }^{*}$ \\
\hline \multirow{2}{*}{ Dairy products } & CHD patient & 1.31 & 0.82 & -4.11 & \multirow{2}{*}{0.001} \\
\hline & Healthy control & 2.15 & 1.18 & -4.11 & \\
\hline \multirow{2}{*}{ Protein rich food } & CHD patient & 2.31 & 2.21 & -0.38 & \multirow{2}{*}{0.70} \\
\hline & Healthy control & 2.44 & 0.87 & -0.38 & \\
\hline \multirow{2}{*}{ Vegetables } & CHD patient & 6.05 & 2.74 & -3.69 & \multirow{2}{*}{0.001} \\
\hline & Healthy control & 8.23 & 3.13 & -3.69 & \\
\hline \multirow{2}{*}{ Fruits } & CHD patient & 4.28 & 3.04 & -2.96 & \multirow{2}{*}{0.004} \\
\hline & Healthy control & 5.96 & 2.61 & -2.96 & \\
\hline \multirow{2}{*}{ Grains } & CHD patient & 12.63 & 4.72 & 1.61 & \multirow{2}{*}{0.10} \\
\hline & Healthy control & 11.29 & 3.45 & 1.61 & \\
\hline \multirow{2}{*}{ Fats \& oils } & CHD patient & 3.05 & 1.83 & 1.10 & \multirow{2}{*}{0.27} \\
\hline & Healthy control & 2.71 & 1.18 & 1.10 & \\
\hline \multirow{2}{*}{ Olive oil } & CHD patient & 1.17 & 1.36 & -6.4 & \multirow{2}{*}{0.51} \\
\hline & Healthy control & 1.31 & 0.68 & -6.4 & \\
\hline \multirow{2}{*}{ Avocado } & CHD patient & 0.20 & 0.37 & -2.39 & \multirow{2}{*}{0.01} \\
\hline & Healthy control & 0.41 & 0.49 & -2.39 & \\
\hline \multirow{2}{*}{ Garlic } & CHD patient & 0.92 & 0.30 & 0.19 & \multirow{2}{*}{0.84} \\
\hline & Healthy control & 0.90 & 0.40 & 0.19 & \\
\hline \multirow{2}{*}{ Nuts \& seeds } & CHD patient & 0.88 & 1.02 & -6.2 & \multirow{2}{*}{0.53} \\
\hline & Healthy control & 1.03 & 1.23 & -6.2 & \\
\hline \multirow{2}{*}{ Sweets } & CHD patient & 2.54 & 2.41 & 2.03 & \multirow{2}{*}{0.04} \\
\hline & Healthy control & 1.78 & 1.01 & 2.03 & \\
\hline
\end{tabular}

${ }^{*}$ Statistically significant at $P$-value $<0.05 .{ }^{* *}$ Standard deviation. 


\section{Discussion}

\subsection{Socioeconomic Factors}

Concerning socioeconomic status in the present study, it was significantly inversely associated with CHD. About smoking, significantly more patients with CHD were smokers. The findings are supported by the study of [21] that found an inverse association between education and the risk of CHD. The study of [22] about CHD risk factors showed a high prevalence of smoking (46.4\%), which ranked the third after dyslipidemia and male gender. In contrast to the present study, a research that evaluated the CV risk factors, compared a group of highranking officials with a group of office workers, and found that officials smoked less, and some CV risk indicators such as WC and TG levels were higher [23]. It is noted that the relationship between socioeconomic status, smoking, and CVD in different studies shows inconsistent results, and needs future research.

\subsection{Exposure to Stress}

The current study revealed a significant positive association between stress and CHD. The stress is recognized by [24] as a risk factor for CHD. In this regard, a prospective cohort study showed a higher risk of CHD in individuals who reported a significant effect of stress on their health compared to those who didn't report [25]. In the current study most patients with CHD had a low socioeconomic status and stress, which contradicts the study of [23] showing that individuals from the high social class had more stress and a higher CV risk.

\subsection{Serum Lipids}

The results indicated that the means of TC, LDL-C and TG levels were higher in patients with CHD, while the mean of HDL-C was significantly lower among cases than controls. These results are supported by the study of [26] about CHD risk factors that found a higher percentage of young adults with CHD or CHD equivalents with high LDL-C levels, compared to those without CHD risk factors. The study of [22] showed that dyslipidemia had the highest prevalence (77.6\%) among the traditional risk factors for CHD. High serum levels of TG and low HDL-C among CHD patients in this study might be due at least partially their dietary habits, with an increased intake of sweets and low intake of healthy fats and oils. Scientific literature states that high-carbohydrate diets seem to produce lower levels of HDL-C, and increased plasma levels of small dense LDL-C and TG [27].

\subsection{Body Mass Index (BMI) and Waist Circumference (WC)}

In this work the mean of BMI and WC was higher in the cases group. Obesity is among the major modifiable CHD risk factors [24]. A review of the participants in the National Health and Nutrition Examination Survey revealed that the 10-year CHD risk (using the Framingham risk score) was positively associated with increasing BMI [28]. On the other hand, Logue et al. [29] study revealed a relationship of obesity with fatal, but not the non-fatal CHD. The obesity among CHD patients in the current study could be explained by their sedentary lifestyle, most of them did not work. This fact was combined with wrong nutritional habits such as higher intake of sweets and lower intake of healthy foods, such as fruits and vegetables.

\subsection{Serum Vitamin D Levels}

This study found an inverse association between serum Vitamin D levels and CHD. The present study is consistent with the study of [30] which revealed that low Vitamin D levels are associated with prevalent CHD. A prospective analysis showed that Vitamin D levels were associated with CV events including coronary artery disease $(P<0.0001)$ [31]. The study of [32] among patients undergoing coronary angiography revealed that most of them (80\%) had Vitamin D deficiency. Observational studies found an association of Vitamin D with cardiometabolic risk, but the evidence from trials is inconsistent. A recent randomized trial in which two groups of premenopausal women with Vitamin D deficiency received either Vitamin D or placebo, showed no improvement of cardiometabolic risk factors, such as blood pressure and serum lipid profile [33]. The high prevalence of Vitamin D deficiency among CHD cases in this study may be related to both, an insufficient exposure to sunlight and a low intake of Vitamin D from food. In addition, Vitamin D synthesis in skin depends on other factors including skin pigment, aging, time of day and season [12], which could also influence the serum levels in this study. 


\subsection{Dietary Habits}

The present study showed that the means of daily intake of dairy products, fruits, vegetables, and avocado were significantly lower in patients with CHD. Olive oil and nuts consumption was insignificantly lower in the cases group. Concerning sweets, the mean intake was higher in CHD patients $(P=0.04)$. About dairy intake, a review of eighteen observational studies has indicated that total dairy intake does not increase CVD risk [34]. Similarly, The Maine-Syracuse Longitudinal Study has revealed a positive relationship between total dairy intake and CV health [35]. However the study conducted by [36] is inconsistent with the present study, and found that women with a higher intake of low-fat cheese and non-fat milk had an increased risk of CHD. Regarding fruits and vegetables, a large observational study concluded that higher intake is associated with a reduced risk of CHD mortality [37]. Bhupatiraju et al. [38] study showed that the quantity, rather than variety in fruits and vegetables intake decreases the risk of CHD. About olive oil and nuts intake, a randomized trial found that a Mediterranean diet rich in olive oil or nuts decreases the incidence of CV events [39]. Regarding avocado, containing MUFA, dietary fiber, phytochemicals and essential nutrients, an observational study showed that in avocado consumers body weight, BMI, and WC were lower $(P<0.01)$ and HDL-C was higher $(P<0.01)$ [40]. Contrasting with the current study, a recent research revealed that intake of monounsaturated fatty acids (MUFA) increased the risk of CHD, but the association between MUFA and CHD requires further studies [41]. Concerning sugars, a previous study found increased odds of CHD for those with highest sweets and desserts intake [42]. The dietary habits of the patients with CHD in the present study expose CV risk. Despite living in the Mediterranean region, the cases of CHD did not adhere well to the Mediterranean diet, which consists of high intake of olive oil, fruit, vegetables and nuts, and low intake of sweets [39], reducing the risk of CHD [27].

\section{Conclusions}

This study explores the relationship of the nutritional determinants, Vitamin D, and serum lipids levels with coronary heart disease. The findings indicated a significant inverse association between socioeconomic status and CHD, while the smoking and stress were significantly positive associated with the CHD. Regarding Vitamin D status, the results showed an inverse association between Vitamin D levels and CHD. Concerning dietary habits, the intake of fruits, vegetables and dairy was lower, and that of sweets was higher in CHD patients, with statistical significance for all. About lipid profile, the means of serum levels of TC, LDL-C and TG were higher, while the mean of HDL-C was significantly lower in the cases group. Concerning anthropometric measures, waist circumference was significantly higher among the cases.

Dietitians can recommend a healthful diet with an increased dairy, fruits and vegetables intake, healthy fats from olive oil, nuts and seeds, while reducing consumption of simple sugars. An effective prevention of CHD should include screening for hyperlipidemia, obesity, and advices for a healthy diet by health providers in Primary Health Care.

\section{References}

[1] World Health Organization (2013) Cardiovascular Diseases (CVDs). WHO Media Centre. http://www.who.int/mediacentre/factsheets/fs317/en/

[2] Ministry of Health (2012) Health Annual Report Palestine 2011.

[3] Royal College of Physicians (2010) Unstable Angina and NSTEMI: The Early Management of Unstable Angina and Non-ST-Segment-Elevation Myocardial Infarction, London, UK. http://www.ncbi.nlm.nih.gov/pubmed/21977549

[4] Nabel, E.G. and Braunwald, E. (2012) A Tale of Coronary Artery Disease and Myocardial Infarction. The New England Journal of Medicine, 366, 54-63. http://dx.doi.org/10.1056/NEJMra1112570

[5] Boudi, F.B. (2014) Risk Factors for Coronary Artery Disease. http://emedicine.medscape.com/article/164163-overview

[6] Olinto, M.T., Gigante, D.P., Horta, B., Silveira, V., Oliveira, I. and Willett, W. (2012) Major Dietary Patterns and Cardiovascular Risk Factors among Young Brazilian Adults. European Journal of Nutrition, 51, 281-291. http://dx.doi.org/10.1007/s00394-011-0213-4

[7] World Health Organization (2014) Unhealthy Diet. WHO Global Health Observatory (GHO). http://www.who.int/gho/ncd/risk_factors/unhealthy_diet_text/en/

[8] Grundy, S.M., Cleeman, J.I., Bairey Merz, C.N., Brewer Jr., H.B., Clark, L.T., Hunninghake, D.B., et al. (2004) NCEP Report. Implications of Recent Clinical Trials for the National Cholesterol Education Program Adult Treatment Panel III Guidelines. Circulation, 110, 227-239. http://dx.doi.org/10.1161/01.CIR.0000133317.49796.0E 
[9] Natarajan, P., Ray, K.K. and Cannon, C.P. (2010) High-Density Lipoprotein and Coronary Heart Disease. Journal of the American College of Cardiology, 55, 1283-1299. http://dx.doi.org/10.1016/j.jacc.2010.01.008

[10] Pejic, R.N. (2011) Should We Treat Moderately Elevated Triglycerides? American Family Physician, 83, $242-245$.

[11] Lavie, C.J., Lee, J.H. and Milani, R.V. (2011) Vitamin D and Cardiovascular Disease, Will It Live up to Its Hype? Journal of American College of Cardiology, 58, 1547-1556. http://dx.doi.org/10.1016/j.jacc.2011.07.008

[12] Holick, M.F. (2014) Sunlight, Ultraviolet Radiation, Vitamin D and Skin Cancer: How Much Sunlight Do We Need? Advances in Experimental Medicine and Biology, 810, 1-16. http://www.ncbi.nlm.nih.gov/pubmed/25207357

[13] Holick, M.F. (2007) Vitamin D Deficiency. The New England Journal of Medicine, 357, 266-281. http://dx.doi.org/10.1056/NEJMra070553

[14] Chung, M., Balk, E.M., Brendel, M., Ip, S., Lau, J., Lee, J., et al. (2009) Vitamin D and Calcium: Systematic Review of Health Outcomes. Evidence Report/Technology Assessment No. 183. (Prepared by Tufts Evidence-Based Practice Center under Contract No. 290-2007-10055-I.)

[15] Kunadian, V., Ford, G.A., Bawamia, B., Qiu, W. and Manson, J.E. (2014) Vitamin D Deficiency and Coronary Artery Disease: A Review of the Evidence. American Heart Journal, 167, 283-291. http://dx.doi.org/10.1016/j.ahj.2013.11.012

[16] Office of Dietary Supplements/National Institutes of Health (2014) Vitamin D Fact Sheet for Health Professionals. http://ods.od.nih.gov/factsheets/VitaminD-HealthProfessional/

[17] World Health Organization (2014) Gaza Strip, Joint Health Sector Assessment Report. Health Cluster in the Occupied Palestinian Territory.

[18] Centers for Disease Control and Prevention, CDC (2011) About BMI for Adults, USA. http://www.cdc.gov/healthyweight/assessing/bmi/adult_bmi/index.html\#Interpreted

[19] American Association for Clinical Chemistry (2013) Lipid Profile: The Test. http://labtestsonline.org/understanding/analytes/lipid/tab/test

[20] Mayo Clinic (2011) Endocrine University: Intensive Technology Training for Clinical Endocrinology Fellows. Endocrinology Update, 6. http://www.mayoclinic.org/documents/mc5810-0911-pdf/doc-20079207

[21] Loucks, E.B., Buka, S.L., Rogers, M.L., Liu, T., Kawachi, I., Kubzansky, L.D., Martin, L.T. and Gilman, S.E. (2012) Education and Coronary Heart Disease Risk Associations May Be Affected by Early Life Common Prior Causes: A Propensity Matching Analysis. Annals of Epidemiology, 22, 221-232. http://dx.doi.org/10.1016/j.annepidem.2012.02.005

[22] Sadeghi, R., Adnani, N., Erfanifar, A., Gachkar, L. and Maghsoomi, Z. (2013) Premature Coronary Heart Disease and Traditional Risk Factors-Can We Do Better? International Cardiovascular Research Journal, 7, 46-50.

[23] Mirmohammadi, S.J., Taheri, M., Mehrparvar, A.H., Heydari, M., Saadati Kanafi, A. and Mostaghaci, M. (2014) Occupational Stress and Cardiovascular Risk Factors in High-Ranking Government Officials and Office Workers. Iranian Red Crescent Medical Journal, 16, e11747. http://dx.doi.org/10.5812/ircmj.11747

[24] American Heart Association (2014) Coronary Artery Disease-Coronary Heart Disease. http://www.heart.org/HEARTORG/Conditions/More/MyHeartandStrokeNews/Coronary-Artery-Disease---Coronary-H eart-Disease_UCM_436416_Article.jsp

[25] Nabi, H., Kivimaki, M., Batty, G.D., Shipley, M.J., Britton, A., Brunner, E.J., et al. (2013) Increased Risk of Coronary Heart Disease among Individuals Reporting Adverse Impact of Stress on Their Health: The Whitehall II Prospective Cohort Study. European Heart Journal, 34, 2697-2705. http://dx.doi.org/10.1093/eurheartj/eht216

[26] Kuklina, E.V., Yoon, P.W. and Keenan, N.L. (2010) Prevalence of Coronary Heart Disease Risk Factors and Screening for High Cholesterol Levels among Young Adults, United States, 1999-2006. Annals of Family Medicine, 8, 327-333. http://dx.doi.org/10.1370/afm.1137

[27] Reddy, K.S. and Katan, M.B. (2004) Diet, Nutrition and the Prevention of Hypertension and Cardiovascular Diseases. Public Health Nutrition, 7, 167-186. http://dx.doi.org/10.1079/PHN2003587

[28] Nguyen, N.T., Nguyen, X.M., Wooldridge, J.B., Slone, J.A. and Lane, J.S. (2010) Association of Obesity with Risk of Coronary Heart Disease: Findings from the National Health and Nutrition Examination Survey, 1999-2006. Surgery for Obesity and Related Diseases, 6, 465-469. http://dx.doi.org/10.1016/j.soard.2010.02.038

[29] Logue, J., Murray, H.M., Welsh, P., Shepherd, J., Packard, C., Macfarlane, P., et al. (2011) Obesity Is Associated with Fatal Coronary Heart Disease Independently of Traditional Risk Factors and Deprivation. Heart, 97, 564-568. http://dx.doi.org/10.1136/hrt.2010.211201 PMid:21324888

[30] Siadat, Z.D., Kiani, K., Sadeghi, M., Shariat, A.S., Farajzadegan, Z. and Kheirmand, M. (2012) Association of Vitamin D Deficiency and Coronary Artery Disease with Cardiovascular Risk Factors. Journal of Research in Medical Sciences, 17, 1052-1055. http://www.ncbi.nlm.nih.gov/pubmed/23833580 
[31] Anderson, J.L., May, H.T., Horne, B.D., Bair, T.L., Hall, N.L., Carlquist, J.F., Lappé, D.L. and Muhlestein, J.B. (2010) Relation of Vitamin D Deficiency to Cardiovascular Risk Factors, Disease Status, and Incident Events in a General Healthcare Population. American Journal of Cardiology, 106, 963-968. http://dx.doi.org/10.1016/j.amjcard.2010.05.027

[32] Syal, S.K., Kapoor, A., Bhatia, E., Sinha, A., Kumar, S., Tewari, S., Garg, N. and Goel, P.K. (2012) Vitamin D Deficiency, Coronary Artery Disease, and Endothelial Dysfunction: Observations from a Coronary Angiographic Study in Indian Patients. The Journal of Invasive Cardiology, 24, 385-389. http://www.ncbi.nlm.nih.gov/pubmed/22865308

[33] Ramly, M., Ming, M.F., Chinna, K., Suboh, S. and Pendek, R. (2014) Effect of Vitamin D Supplementation on Cardiometabolic Risks and Health-Related Quality of Life among Urban Premenopausal Women in a Tropical CountryA Randomized Controlled Trial. PLoS ONE, 9, e110476. http://dx.doi.org/10.1371/journal.pone.0110476

[34] Rice, B.H. (2014) Dairy and Cardiovascular Disease: A Review of Recent Observational Research. Current Nutrition Reports, 15, 130-138. http://www.ncbi.nlm.nih.gov/pmc/articles/PMC4006120/

[35] Crichton, G.E. and Elias, M.F. (2014) Dairy Food Intake and Cardiovascular Health: The Maine-Syracuse Study. Advances in Dairy Research, 2, 112. http://dx.doi.org/10.4172/2329-888X.1000112

[36] Avalos, E.E., Barrett-Connor, E., Kritz-Silverstein, D., Wingard, D.L., Bergstrom, J.N. and Al-Delaimy, W.K. (2013) Is Dairy Product Consumption Associated with the Incidence of CHD? Public Health Nutrition, 16, 2055-2063. http://dx.doi.org/10.1017/S1368980012004168

[37] Crowe, F.L., Roddam, A.W., Key, T.J., Appleby, P.N., Overvad, K., Jakobsen, M.U., et al. (2011) Fruit and Vegetable Intake and Mortality from Ischaemic Heart Disease: Results from the European Prospective Investigation into Cancer and Nutrition (EPIC)-Heart Study. European Heart Journal, 32, 1235-1243. http://dx.doi.org/10.1093/eurheartj/ehq465

[38] Bhupathiraju, S.N., Wedick, N.M., Pan, A., Manson, J.E., Rexrode, K.M., Willett, W.C., Rimm, E.B. and Hu, F.B. (2013) Quantity and Variety in Fruit and Vegetable Intake and Risk of Coronary Heart Disease. American Journal of Clinical Nutrition, 98, 1514-1523. http://dx.doi.org/10.3945/ajcn.113.066381

[39] Estruch, R., Ros, E., Salas-Salvadó, J., Covas, M.I., Corella, D., Arós, F., et al. (2013) Primary Prevention of Cardiovascular Disease with a Mediterranean Diet. The New England Journal of Medicine, 368, 1279-1290. http://dx.doi.org/10.1056/NEJMoa1200303

[40] Fulgoni, V.L., Dreher, M. and Davenport, A.J. (2013) Avocado Consumption Is Associated with Better Diet Quality and Nutrient Intake, and Lower Metabolic Syndrome Risk in US Adults: Results from the National Health and Nutrition Examination Survey (NHANES) 2001-2008. Nutrition Journal, 12, 1.

[41] Virtanen, J.K., Mursu, J., Tuomainen, T.P. and Voutilainen, S. (2014) Atherosclerosis/Lipoproteins, Dietary Fatty Acids and Risk of Coronary Heart Disease in Men. The Kuopio Ischemic Heart Disease Risk Factor Study. Arteriosclerosis, Thrombosis, and Vascular Biology, 34, 2679-2687. http://dx.doi.org/10.1161/ATVBAHA.114.304082

[42] Moghadam, E.F., Tadevosyan, A., Kimiagar, M. and Chamari, M. (2012) An Assessment of Dietary Intake Associated with the Coronary Heart Disease among Adults in Yerevan, Armenia. Life Science Journal, 9, 865-870. 
Scientific Research Publishing (SCIRP) is one of the largest Open Access journal publishers. It is currently publishing more than 200 open access, online, peer-reviewed journals covering a wide range of academic disciplines. SCIRP serves the worldwide academic communities and contributes to the progress and application of science with its publication.

Other selected journals from SCIRP are listed as below. Submit your manuscript to us via either submit@scirp.org or Online Submission Portal.
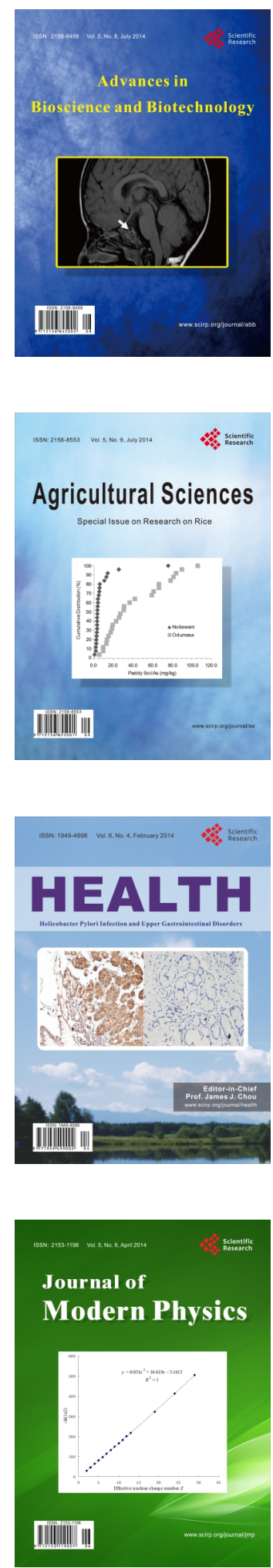
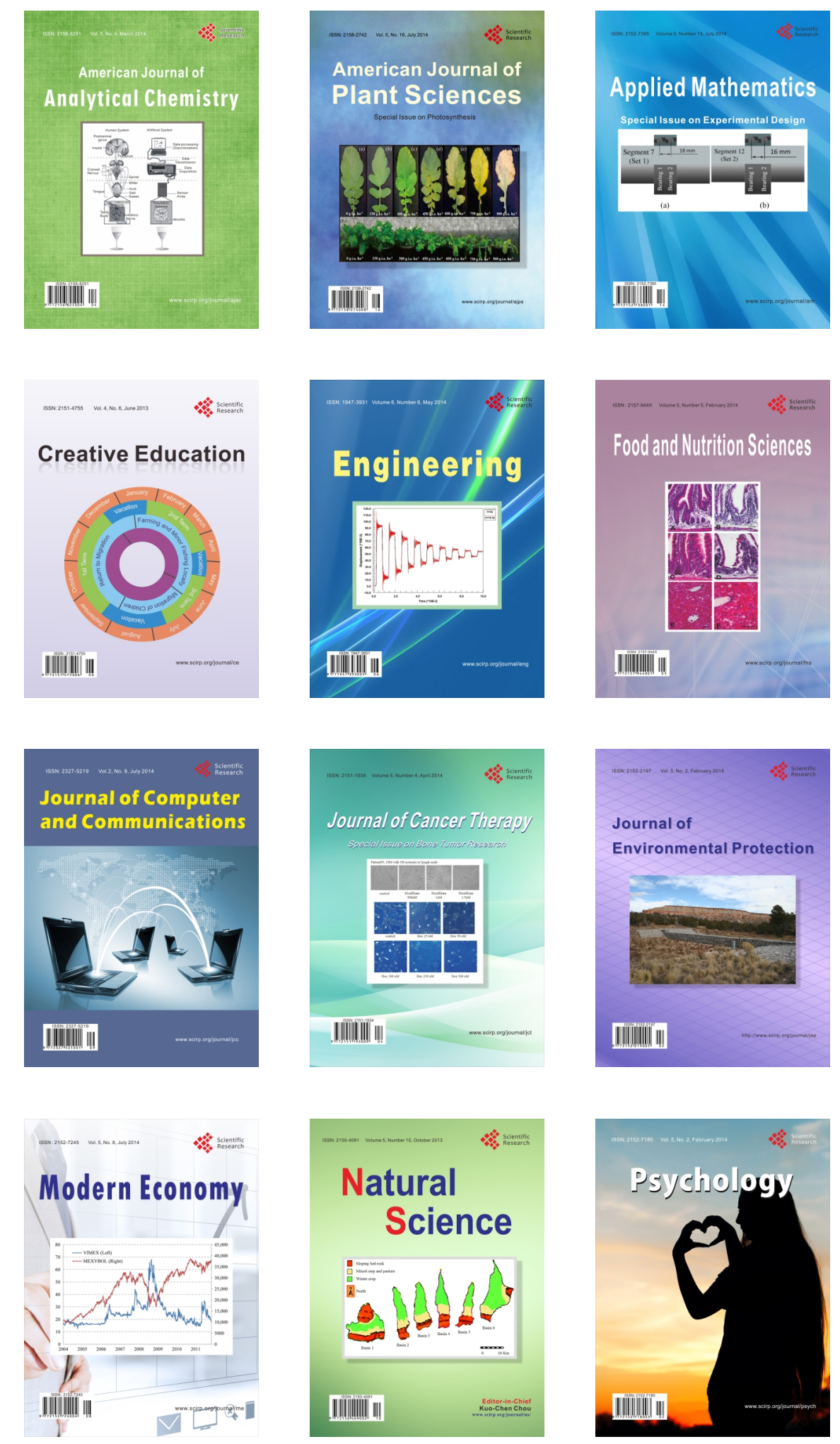